\title{
Modulation of mitochondrial respiratory function and ROS production by novel benzopyran analogues ${ }^{1}$
}

\author{
Alexandra Petruş, Oana M. Duicu, Adrian Sturza, Lavinia Noveanu, Loránd Kiss, Maria Dănilă, \\ István Baczkó, Danina M. Muntean, and Norbert Jost
}

\begin{abstract}
A substantial body of evidence indicates that pharmacological activation of mitochondrial ATP-sensitive potassium channels $\left(\mathrm{mK}_{\text {АтP }}\right)$ in the heart is protective in conditions associated with ischemia/reperfusion injury. Several mechanisms have been postulated to be responsible for cardioprotection, including the modulation of mitochondrial respiratory function. The aim of the present study was to characterize the dose-dependent effects of novel synthetic benzopyran analogues, derived from a BMS-191095, a selective $\mathrm{mK}_{\mathrm{ATP}}$ opener, on mitochondrial respiration and reactive oxygen species (ROS) production in isolated rat heart mitochondria. Mitochondrial respiratory function was assessed by high-resolution respirometry, and $\mathrm{H}_{2} \mathrm{O}_{2}$ production was measured by the Amplex Red fluorescence assay. Four compounds, namely KL-1487, KL-1492, KL-1495, and KL-1507, applied in increasing concentrations $(50,75,100$, and $150 \mu \mathrm{mol} / \mathrm{L}$, respectively) were investigated. When added in the last two concentrations, all compounds significantly increased State 2 and 4 respiratory rates, an effect that was not abolished by 5-hydroxydecanoate (5-HD, $100 \mu \mathrm{mol} / \mathrm{L})$, the classic $\mathrm{mK}_{\mathrm{ATP}}$ inhibitor. The highest concentration also elicited an important decrease of the oxidative phosphorylation in a $\mathrm{K}^{+}$independent manner. Both concentrations of 100 and $150 \mu \mathrm{mol} / \mathrm{L}$ for KL-1487, KL-1492, and KL-1495, and the concentration of $150 \mu \mathrm{mol} / \mathrm{L}$ for KL-1507, respectively, mitigated the mitochondrial $\mathrm{H}_{2} \mathrm{O}_{2}$ release. In isolated rat heart mitochondria, the novel benzopyran analogues act as protonophoric uncouplers of oxidative phosphorylation and decrease the generation of reactive oxygen species in a dose-dependent manner.
\end{abstract}

Key words: rat heart mitochondria, benzopyran analogues, protonophores, uncoupling, hydrogen peroxide.

Résumé : De plus en plus de données indiquent que l'activation pharmacologique des canaux potassiques sensibles à l'ATP de la mitochondrie $\left(\mathrm{mK}_{\mathrm{ATP}}\right)$ du cœur le protège lorsqu'il est exposé à des conditions associées au dommage d'ischémie/reperfusion. Plusieurs mécanismes pourraient être responsables de la cardioprotection incluant la modulation de la fonction respiratoire mitochondriale. Le but de l'étude présente était de caractériser les effets liés à la dose de nouveaux analogues synthétiques du benzopyrane, dérivés du BMS-191095, un composé qui ouvre sélectivement les $\mathrm{mK}_{\mathrm{ATP}}$, sur la respiration mitochondriale et la production d'espèces réactives d'oxygène (ERO) dans les mitochondries isolées du cour de rat et ce. La fonction respiratoire mitochondriale a été évaluée par respirométrie à haute résolution et la production de $\mathrm{H}_{2} \mathrm{O}_{2}$ a été mesurée par un dosage en fluorescence à l'aide de la trousse Amplex Red. Quatre composés, à savoir KL-1487, KL-1492, KL-1495 et KL-1507, ajoutés en concentrations croissantes (50, 75, 100 et $150 \mu \mathrm{mol} / \mathrm{L}$, respectivement), ont été examinés. Lorsqu'ajoutés aux deux concentrations les plus élevées, tous les composés accroissaient significativement les taux respiratoires aux états 2 et 4 , effet qui n'était pas aboli par le 5-hydroxydécanoate (5-HD, $100 \mu \mathrm{mol} / \mathrm{L})$, l'inhibiteur classique des $\mathrm{mK}_{\mathrm{ATP}}$. La plus forte concentration induisait aussi une diminution importante de la phosphorylation oxydative de manière indépendante du $\mathrm{K}^{+}$. Les deux concentrations de $100 \mu \mathrm{mol} / \mathrm{L}$ et $150 \mu \mathrm{mol} / \mathrm{L}$ de KL-1487, KL-1492 et KL-1495, et la concentration de $150 \mu \mathrm{mol} / \mathrm{L}$ de KL-1507 diminuaient respectivement la libération de $\mathrm{H}_{2} \mathrm{O}_{2}$ de la mitochondrie. Les nouveaux analogues du benzopyrane agissent comme découplants protonophores de la phosphorylation oxydative dans les mitochondries isolées du cœur de rat, et diminuent la génération d'espèces réactives d'oxygène en fonction de leur concentration. [Traduit par la Rédaction]

Mots-clés : mitochondries du cœur de rat, analogues du benzopyrane, protonophores, effet découplant, peroxyde d'hydrogène.

\section{Introduction}

In the past decades mitochondria have emerged as major contributors to the pathogenesis of myocardial ischemia/reperfusion (I/R) injury as well as important therapeutic targets in cardioprotection (Camara et al. 2011; Di Lisa et al. 2007). The mitochondrial ATP-sensitive potassium channel $\left(\mathrm{mK}_{\mathrm{ATP}}\right)$ is one of the putative structures at the inner mitochondrial membrane that has been extensively studied in several experimental models as a major target that can be modulated by pharmacological agents and conditioning strategies to protect the heart against the deleterious effects of reoxygenation/reperfusion (critically reviewed by Hanley and Daut (2005). The channel functions as potassium uniporter, allowing the ions intake into the matrix and is inhibited by ATP, ADP, and fatty acids (Cardoso et al. 2010; Garlid and

Received 26 January 2015. Accepted 24 June 2015.

A. Petruş* and I. Baczkó. Department of Pathophysiology, "Victor Babeş” University of Medicine and Pharmacy of Timişoara, 14, Tudor Vladimirescu st. 300173 Timisoara, Romania.

O.M. Duicu,* A. Sturza, L. Noveanu, M. Dănilă, D.M. Muntean, and N. Jost. Department of Pathophysiology, Center for Translational Research and Systems Medicine, "Victor Babeş" University of Medicine and Pharmacy of Timişoara, Romania.

L. Kiss. Institute of Pharmaceutical Chemistry, Faculty of Pharmacy, University of Szeged, Szeged, Hungary.

Corresponding author: Danina Muntean (e-mail: daninamuntean@umft.ro).

*These authors contributed equally to this work.

'This article is part of a Special Issue entitled "Cardioprotection and Arrhythmias, Part 2." 
Halestrap 2012). Despite the fact that the first reconstitution of the $\mathrm{mK}_{\text {ATP }}$ protein isolated from bovine heart in liposomes had been reported more than two decades ago (Paucek et al. 1992), the molecular structure of the channel still remains inconclusive; therefore, the role in cardioprotection and, even their existence, has been recently questioned (Garlid and Halestrap 2012).

Several research groups performed over the years a thorough functional characterization using the pharmacological approach, i.e., application of channel openers (agonists) or blockers (antagonists) and provided evidence for the role of $\mathrm{mK}_{\mathrm{ATP}}$ in the regulation of mitochondrial matrix volume, calcium uptake, respiration, and reactive oxygen species (ROS) generation (reviewed in Ardehali and O'Rourke (2005) and Nishida et al. (2010)). It has also been reported that potassium channel openers act as uncoupling protonophores and thus contribute to cardioprotection (Holmuhamedov et al. 2004).

The role of $\mathrm{mK}_{\mathrm{ATP}}$ in preventing the oxidative stress is particularly important during the postischemic reperfusion, when mitochondria are both sources and targets of the oxidative burst (Di Lisa 2001; Turrens 2003). The contribution of channel's opening to ROS production is controversial, since both a decrease (Ferranti et al. 2003; Vanden Hoek et al. 2000) and an increase in mitochondrial ROS in the presence of $\mathrm{mK}_{\mathrm{ATP}}$ agonists (Forbes et al. 2001; Krenz et al. 2002; Liu et al. 1998; Pain et al. 2000) have been reported in the literature.

One of the confounding factors regarding the pharmacological approach in studies reporting on cardioprotective effects of $\mathrm{mK}_{\text {ATP }}$ openers is related to the lack of selectivity of the first developed agonists that were able to activate both the mitochondrial and sarcolemmal ATP-sensitive channels (Hanley and Daut 2005). In the attempt to increase the selectivity versus $\mathrm{mK}_{\mathrm{ATP}}$, several benzopyran conjugates have been developed and tested in the past years (reviewed in Breschi et al. (2006)). Among these compounds, BMS-191095 is a 4-(N-aryl)-substituted benzopyran reputed to have the highest $\mathrm{mK}_{\mathrm{ATP}}$ selectivity and anti-ischemic potency (Mannhold 2004). Its beneficial effects were demonstrated not only in the heart (Grover et al. 2001, 2002) but also in cultured cortical neurons (Gaspar et al. 2008; Mayanagi et al. 2007), and a skeletal muscle cell line (Malinska et al. 2010).

The present study was aimed at characterizing the effects of four novel synthetic benzopyran compounds (Fig. 1), structural analogues of BMS-191095 that have been proposed to act as $\mathrm{mK}_{\text {ATP }}$ openers, on mitochondrial respiration and ROS release in isolated rat heart mitochondria.

\section{Materials and methods}

All experimental procedures were conducted in accordance with Directive 2010/63/EU and the corresponding Romanian law nr. 43/May 2014 regarding the protection of animals used for scientific purposes, respectively. The experimental protocol was approved by the Committee for Research Ethics of "Victor Babeş" University for Medicine and Pharmacy of Timişoara, Romania.

Experiments were performed on Sprague Dawley (SD) adult female rats (4-6 months, $n=5-6 /$ group). Animals were fed ad libitum and housed under standard conditions (constant temperature and humidity of $22.5 \pm 2{ }^{\circ} \mathrm{C}$ and $55+5 \%, 12 \mathrm{~h}$ light/dark cycle). Twenty-four hours prior to experiment, solid food was withdrawn with no limitation in water supply.

\section{Rat heart mitochondria (RHM) isolation}

Rats were anesthetized by the intraperitoneal administration of a mixture of ketamine $(30 \mathrm{mg} / \mathrm{kg}$ ) and xylazine $(5 \mathrm{mg} / \mathrm{kg})$. Hearts were rapidly excised and immersed in $20 \mathrm{~mL}$ isolation medium (100 mmol/L sucrose, $50 \mathrm{mmol} / \mathrm{L} \mathrm{KCl}, 20 \mathrm{mmol} / \mathrm{L}$ TES-2-[(2-hydroxy1,1-bis(hydroxymethyl)ethyl)amino]ethanesulfonic acid, $1 \mathrm{mmol} / \mathrm{L}$ EDTA, $0.2 \%$ bovine serum albumin (BSA), pH 7.2 at $4{ }^{\circ} \mathrm{C}$ ). Separate experiments were performed in mitochondria isolated in $\mathrm{K}^{+}$free medium $(220 \mathrm{mmol} / \mathrm{L}$ manitol, $70 \mathrm{mmol} / \mathrm{L}$ sucrose, $5 \mathrm{mmol} / \mathrm{L} \mathrm{N}$ [tris(hydroxymethyl)methyl]-2-aminoethanesulfonic acid (TES),
$0.5 \mathrm{mmol} / \mathrm{L}$ EGTA, supplemented with $2 \mathrm{mg} / \mathrm{mL}$ bovine serum albumin (BSA), $\mathrm{pH} 7.4$, adjusted with Trizma base; $2{ }^{\circ} \mathrm{C}$ ). Ventricular tissue was manually triturated with subtilisin $(5 \mathrm{mg} / \mathrm{g}$ wet tissue), a non-specific protease, to release the interfibrillar mitochondria. The suspension was homogenised with a tissue homogenizer (Glas-Col 099C K5424 CE) for maximum $30 \mathrm{~s}$. The final tissue homogenate obtained was processed at $4{ }^{\circ} \mathrm{C}$ using the differential centrifugation technique as previously described (Duicu et al. 2013). Mitochondrial protein concentration was determined using biuret method (Gornall et al. 1949).

\section{High-resolution respirometry experiments}

Oxygen consumption was measured at $37^{\circ} \mathrm{C}$ by high-resolution respirometry (HRR) with the Oxygraph-2k (Oroboros Instruments, Austria). RHM (0.1 mg proteins $/ \mathrm{mL}$ ) were incubated in $2 \mathrm{~mL}$ of incubation medium $\left(0.5 \mathrm{mmol} / \mathrm{L}\right.$ EGTA, $3 \mathrm{mmol} / \mathrm{L} \mathrm{MgCl} 2 \cdot 6 \mathrm{H}_{2} \mathrm{O}$, $60 \mathrm{mmol} / \mathrm{L} \mathrm{K}$-lactobionate, $20 \mathrm{mmol} / \mathrm{L}$ taurine, $10 \mathrm{mmol} / \mathrm{L} \mathrm{KH}_{2} \mathrm{PO}_{4}$, $20 \mathrm{mmol} / \mathrm{L}$ HEPES (4-(2-hydroxyethyl)-1-piperazineethanesulfonic) acid, $110 \mathrm{mmol} / \mathrm{L}$ sucrose, $1 \mathrm{~g} / \mathrm{L}$ BSA, essentially free fatty acid + $280 \mathrm{U} / \mathrm{mL}$ catalase lyophilized powder, 2000-5000 units/mg protein, at $\mathrm{pH} 7.1,37^{\circ} \mathrm{C}$ ). In separate experiments, mitochondrial respiratory rates were measured in $\mathrm{KCl}$ incubation medium $\left(120 \mathrm{mmol} / \mathrm{L} \mathrm{KCl}, 5 \mathrm{mmol} / \mathrm{L} \mathrm{KH}_{2} \mathrm{PO}_{4}, 5 \mathrm{mmol} / \mathrm{L} \mathrm{TES}\right.$, and $1 \mathrm{mmol} / \mathrm{L}$ $\mathrm{MgCl}_{2}$, pH 7.4, adjusted with Trizma base at $37^{\circ} \mathrm{C}$ ) or in choline chloride medium $\left(120 \mathrm{mmol} / \mathrm{L}\right.$ choline chloride, $5 \mathrm{mmol} / \mathrm{L} \mathrm{NaH}_{2} \mathrm{PO}_{4}$, $5 \mathrm{mmol} / \mathrm{L} \mathrm{TES}$, and $1 \mathrm{mmol} / \mathrm{L} \mathrm{MgCl}_{2}, \mathrm{pH} 7.4$, adjusted with Trizma base at $37^{\circ} \mathrm{C}$ ).

The substrate-uncoupler-inhibitor-titration (SUIT) protocol, $\mathrm{GM}_{\text {State } 2}+\mathrm{ADP}_{\text {OXPHOS }}+\mathrm{c}+\mathrm{Omy}_{\text {State } 4}+\mathrm{FCCP}_{\mathrm{ETS}}+(\mathrm{Ama})_{\mathrm{ROX}}$, was previously described (Duicu et al. 2013) and comprised the following steps: (i) addition of complex I respiratory substrates, $10 \mathrm{mmol} / \mathrm{L}$ glutamate $(\mathrm{G})$ and $2 \mathrm{mmol} / \mathrm{L}$ malate $(\mathrm{M})$, State 2 (basal respiration); (ii) addition of $5 \mathrm{mmol} / \mathrm{L}$ adenosine diphosphate (ADP) to assess the maximal oxidative phosphorylation capacity (OXPHOS), State 3 (active respiration); (iii) addition of $10 \mu \mathrm{mol} / \mathrm{L}$ cytochrome c (c) to check for the integrity of mitochondrial outer membrane; (iv) addition of $2 \mu \mathrm{g} / \mathrm{mL}$ oligomycin (Omy), an $\mathrm{F}_{0} \mathrm{~F}_{1}$-ATP synthase inhibitor, to inhibit State 3 at the level of State 4 ; $(v)$ successive titrations $(0.5 \mu \mathrm{mol} / \mathrm{L}$ steps) with FCCP (carbonyl cyanide $p$-(trifluoro-methoxy) phenyl-hydrazone) to obtain the uncoupled respiration and to measure the electron transport system capacity, ETS; (vi) inhibition of respiration with $2.5 \mu \mathrm{mol} / \mathrm{L}$ antimycin A (Ama) to measure the residual oxygen consumption, ROX state. Mitochondrial respiration was corrected for oxygen flux due to instrumental background and ROX. The respiratory control ratio (RCR) was calculated as the ratio OXPHOS/State 4.

\section{Assessment of hydrogen peroxide $\left(\mathrm{H}_{2} \mathrm{O}_{2}\right)$ production}

Mitochondrial $\mathrm{H}_{2} \mathrm{O}_{2}$ release was measured using the Amplex Red $(10 \mu \mathrm{mol} / \mathrm{L})$ fluorescent marker (wavelengths: excitation at $530 \mathrm{~nm}$ and emission at $590 \mathrm{~nm}$, Hitachi F-7000 spectrofluorimeter) as previously described (Duicu et al. 2013). RHM $(0.25 \mathrm{mg}$ protein $/ \mathrm{mL}$ ) were incubated in $2 \mathrm{~mL}$ incubation buffer $(250 \mathrm{mmol} / \mathrm{L}$ sucrose, $1 \mathrm{mmol} / \mathrm{L}$ EGTA, $1 \mathrm{mmol} / \mathrm{L}$ EDTA, $20 \mathrm{mmol} / \mathrm{L} \mathrm{Tris} / \mathrm{HCl}$, and $1.5 \mathrm{mg} / \mathrm{mL}$ defatted BSA, pH 7.4, $37{ }^{\circ} \mathrm{C}$ ), supplemented with CI-dependent substrates: $\mathrm{G}(5 \mathrm{mmol} / \mathrm{L})$ and $\mathrm{M}(5 \mathrm{mmol} / \mathrm{L})$. At the beginning of each measurement, the background fluorescence was quantified by adding known amounts of $\mathrm{H}_{2} \mathrm{O}_{2}$ to the incubation buffer, in the absence of mitochondria. Net fluorescence was then calculated by measuring the fluorescence variation in function of time, minus background, and $\mathrm{H}_{2} \mathrm{O}_{2}$ production was expressed in pmol $\mathrm{H}_{2} \mathrm{O}_{2} / \mathrm{min} / \mathrm{mg}$ proteins.

\section{Chemicals}

The benzopyran analogues were synthesized by Kiss Lorand at the Institute of Pharmaceutical Chemistry, Faculty of Pharmacy, University of Szeged, Hungary. Calcium Green-5N and Amplex 
Fig. 1. Chemical structures of the four synthetic benzopyran analogues.

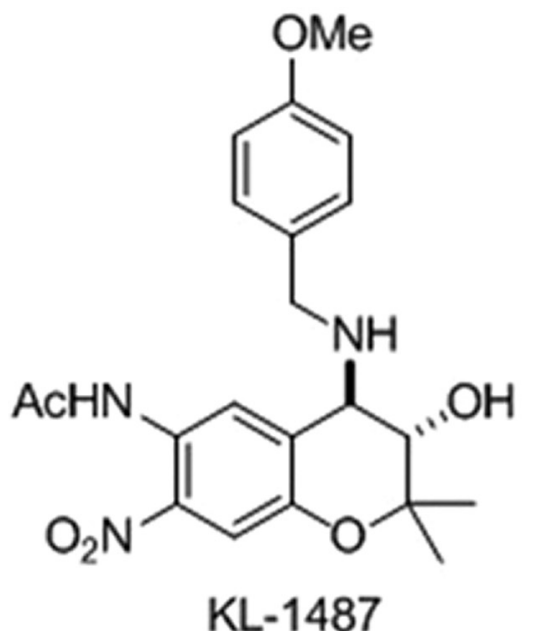<smiles>CC1(C)Oc2cc([N+](=O)[O-])c(N=CC(=O)O)cc2[C@@H](NCc2ccc(Cl)c(F)c2)[C@@H]1O</smiles><smiles></smiles><smiles>CC1(C)Oc2ccc(C#N)cc2[C@@H](n2cc(-c3ccccc3)nn2)[C@H]1O</smiles>

Red were purchased from Invitrogen. All the other chemicals were from Sigma-Aldrich.

\section{Statistical analysis}

Data were expressed as means \pm SEM. Data analysis used oneway ANOVA followed by a post-hoc Tukey's multiple comparison test (GraphPadPrism v. 5.0 Software, SUA). The difference was considered statistically significant if $p<0.05$.

\section{Results and discussion}

\section{High-resolution respirometry}

Four benzopyran derivatives, namely KL-1487, KL-1492, KL-1495, and KL-1507, in increasing concentrations $(50,75,100$, and $150 \mu \mathrm{mol} / \mathrm{L}$, respectively) were screened. Stock solutions of benzopyran analogues were made up in DMSO $(60 \mathrm{mmol} / \mathrm{L})$ and then serially diluted to give the above mentioned concentrations. The final DMSO concentration was constant $(0.25 \%)$ throughout the experiments and did not influence the respiratory rates (data not shown).

The major finding of this work is that we report a dosedependent modulation of the mitochondrial respiratory function for all investigated compounds. Accordingly, a significant increase in respiratory State 4 (Table 1, Fig. 2) was recorded when the compounds were added in the highest concentrations (150 and $100 \mu \mathrm{mol} / \mathrm{L}$ ). The maximum increase was found for KL-1492, while the lowest yet significant change was found in the case of KL-1507 (Table 1, Fig. 2).

Table 1. Respiratory rates in RHM in the presence of CI substrates (glutamate+malate).

\begin{tabular}{llcl}
\hline & $\begin{array}{l}\text { OXPHOS decrease } \\
\text { vs. Ctrl }\end{array}$ & $\begin{array}{l}\text { State 4 increase } \\
\text { vs. Ctrl }\end{array}$ & $\begin{array}{l}\text { RCR decrease } \\
\text { vs. Ctrl }\end{array}$ \\
\hline KL-1487 150 $\mu \mathrm{M}$ & $74,2 \%$ & $96.4 \%$ & $76.3 \%$ \\
KL-1487 100 $\mu \mathrm{M}$ & - & $78.4 \%$ & - \\
KL-1492 150 $\mu \mathrm{M}$ & $57,7 \%$ & $140.8 \%$ & $80.4 \%$ \\
KL-1492 100 $\mu \mathrm{M}$ & - & $74.8 \%$ & $56.43 \%$ \\
KL-1495 150 $\mu \mathrm{M}$ & $56.7 \%$ & $104 \%$ & $79 \%$ \\
KL-1495 100 $\mu \mathrm{M}$ & - & $64 \%$ & $71.62 \%$ \\
KL-1507 150 $\mu \mathrm{M}$ & $48.3 \%$ & $64.6 \%$ & $37.58 \%$ \\
KL-1507 100 $\mu \mathrm{M}$ & - & $64.2 \%$ & - \\
\hline
\end{tabular}

Note: Data are expressed as percentage changes of mitochondrial respiratory rates in treated groups vs. Ctrls (100\%).

However, when applied in the maximal concentration $(150 \mu \mathrm{mol} / \mathrm{L})$, all compounds induced a significant decrease in OXPHOS (State 3 , ADP-stimulated respiration) vs. control (Ctrl), with the most important inhibition recorded for KL-1487 (Table 1, Fig. 3). These effects (increase in State 4 together with the decrease in OXPHOS) for $150 \mu \mathrm{mol} / \mathrm{L}$ resulted in a significant reduction of the respiratory index (OXPHOS/State 4) vs. Ctrl for all tested compounds (Table 1, Fig. 4).

As mentioned in the previous section, State 2 represents the basal respiration, whereas State 4 was pharmacologically induced 
Fig. 2. State 4 respiratoy rates in the presence of K-1487, KL-1492, KL-1495, and KL-1507. Results are expressed in pmol/(s·mL). Values are means \pm SEM $\left({ }^{*} p<0.05 ;{ }^{* *} p<0.01 ;{ }^{* * *} p<0.001\right.$ vs. Ctrl).
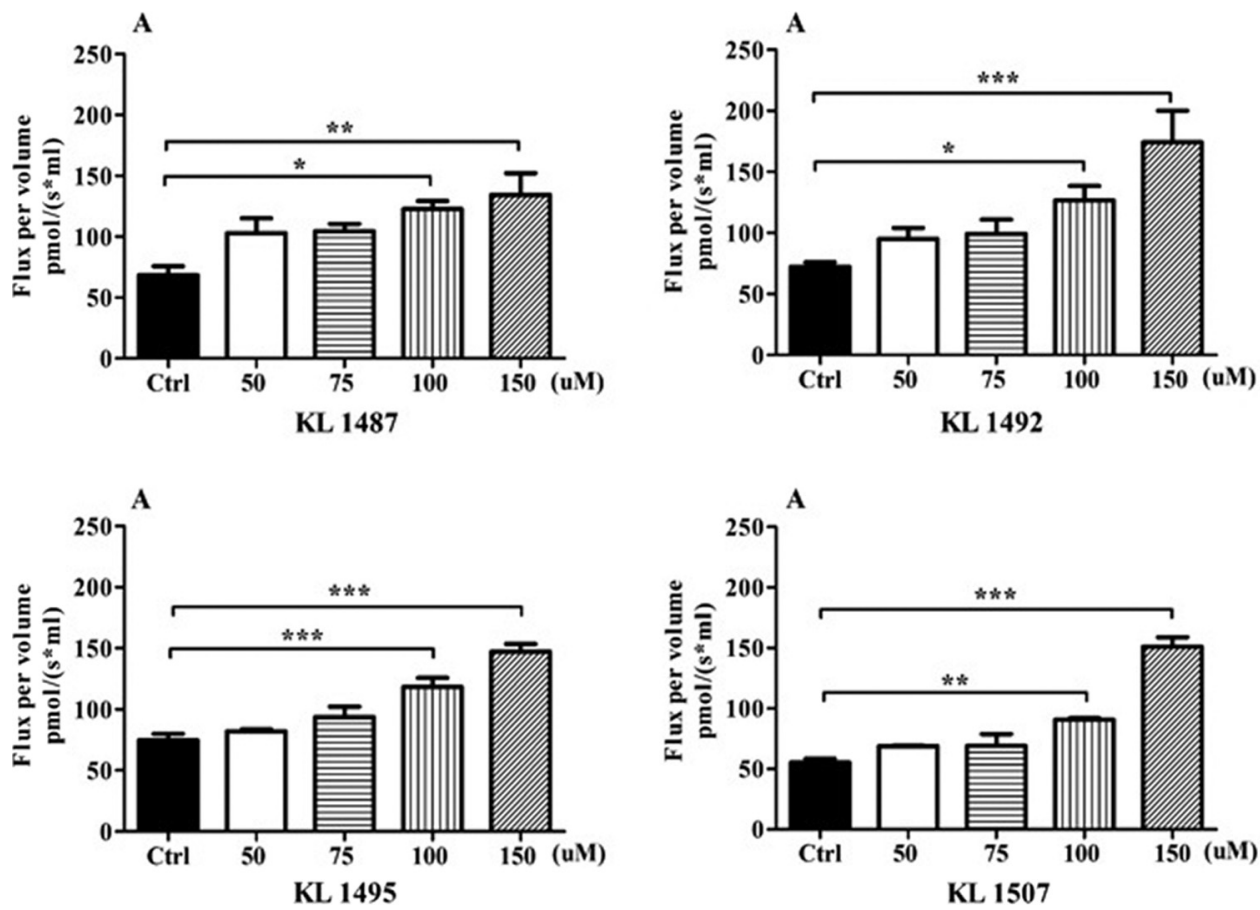

Fig. 3. OXPHOS respiratory rates in the presence of K-1487, KL-1492, KL-1495, and KL-1507. Results are expressed in pmol/(s·mL). Values are means $\pm \operatorname{SEM}\left({ }^{* *} p<0.01 ;{ }^{* * *} p<0.001\right.$ vs. Ctrl).
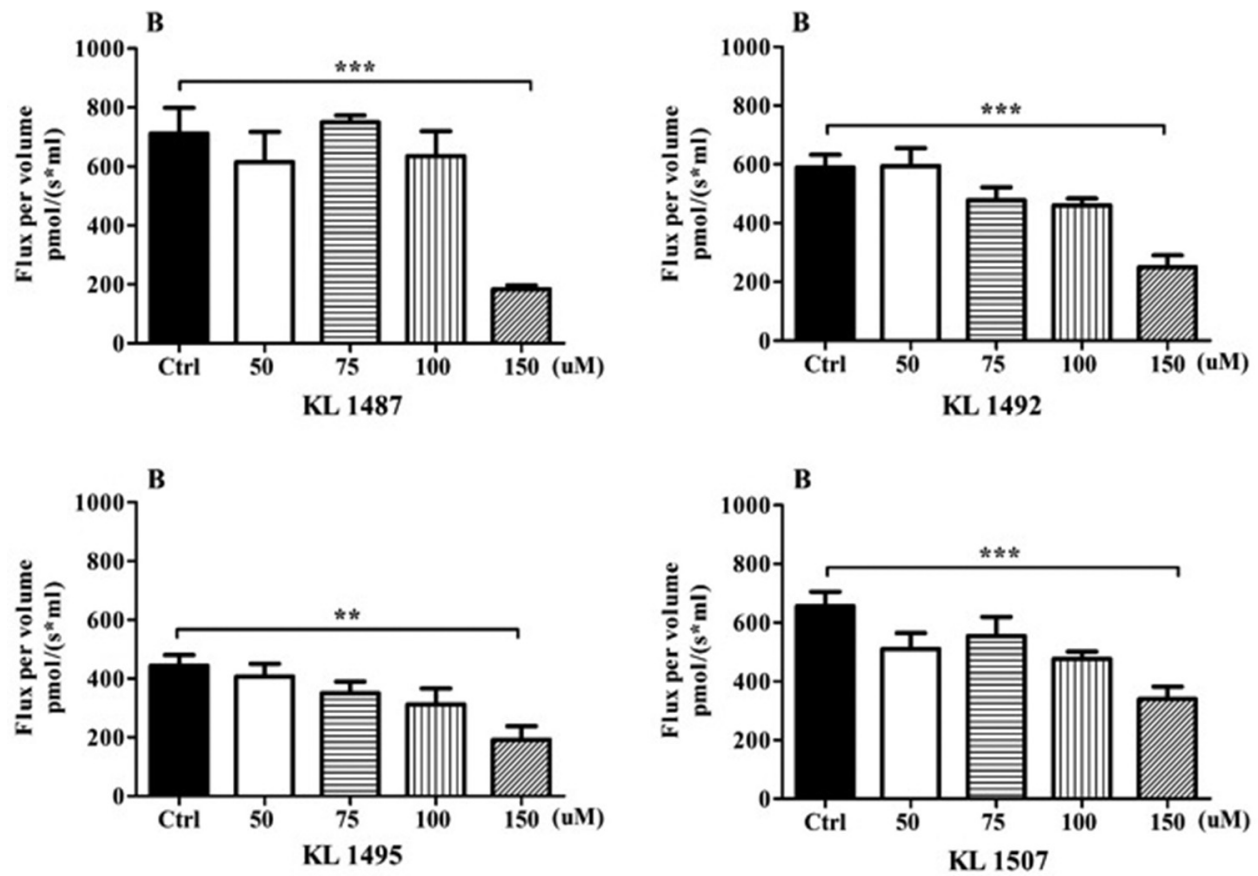

with oligomycin (Omy), which inhibits the proton entry at the level of $\mathrm{F}_{0}$-ATPase. Compounds able to stimulate respiratory rates in State 4 (and 2) in a dose-dependent fashion are known as uncouplers, because they disrupt (or uncouple) the link between substrate oxidation and ADP phosphorylation in ATP. Conversely, mitochondrial respiration that has been inhibited by inhibitors such as antimycin cannot be released by the uncouplers (Terada 1990).

Data presented in this study suggest that all four investigated compounds act as inhibitory uncouplers, showing an intrinsic

uncoupling effect with increasing concentrations and inhibitory property when used in the highest doses. Indeed, starting from $50 \mu \mathrm{mol} / \mathrm{L}$, these benzopyran analogues uncoupled the oxidative phosphorylation of mitochondria respiring on the NAD-dependent substrates glutamate-malate.

We further tested the effects of 5-hydroxydecanoate (5-HD, $100 \mu \mathrm{mol} / \mathrm{L}$ ), which is known as putative selective $\mathrm{mK}_{\mathrm{ATP}}$ inhibitor. Our data clearly demonstrated that the uncoupling effect induced by all four benzopyran analogues was not abolished by 5-HD 
Fig. 4. RCR in the presence of K-1487, KL-1492, KL-1495, and KL-1507. Values are means \pm SEM $\left({ }^{*} p<0.05 ;{ }^{* *} p<0.01 ; * * *<0.001\right.$ vs. Ctrl).

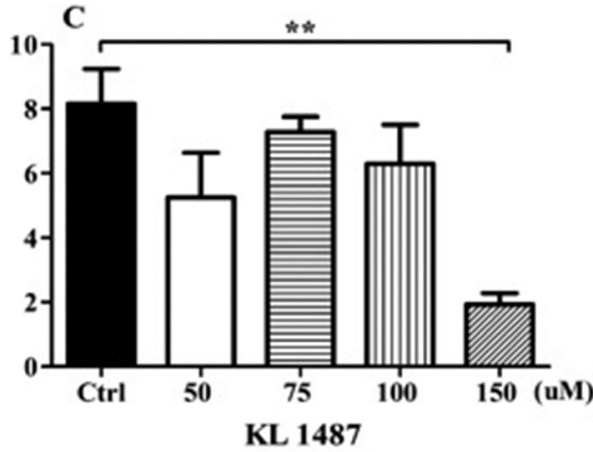

C

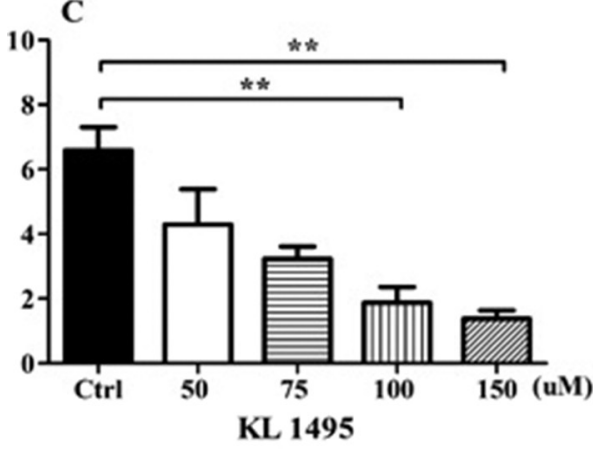

(Table 2), suggesting that the increase in CI-supported basal respiration was not related to the opening of $\mathrm{mK}_{\mathrm{ATP}}$ channels. Our findings agrees with the well-established effects of the $\mathrm{mK}_{\text {ATP }}$ openers, diazoxide and pinacidil, that act as uncoupling protonophores, mainly when applied in high concentrations, in isolated rodent mitochondrial preparations (Drose et al. 2006; Hanley et al. 2002; Holmuhamedov et al. 2004; Kopustinskiene et al. 2002; Korotkov et al. 2006; Kowaltowski et al. 2001) in a potassium channel-independent manner. Also, our data regarding the effect of 5-HD are in agreement with the previous reports showing that the $\mathrm{mK}_{\text {ATP }}$ blocker had no effect on the activation of the basal mitochondrial respiration by diazoxide and pinacidil applied in similar concentrations (Kopustinskiene et al. 2010; Korotkov et al. 2006). Furthermore, all four compounds significantly decreased State 3 respiration as was earlier demonstrated for diazoxide (Kopustinskiene et al. 2002; Rousou et al. 2004) and pinacidil (Kopustinskiene et al. 2010).

To investigate whether the decrease of State 3 respiratory rate can be assigned to the $\mathrm{mK}_{\mathrm{ATP}}$ opening, we recapitulated the experiments on mitochondria isolated in free potassium media, and we measured the respiratory rates in potassium chloride and choline chloride medium (without $\mathrm{K}^{+}$). Since the effect of all four compounds at $150 \mu \mathrm{mol} / \mathrm{L}$ on State 3 respiration remained unchanged (Fig. 5) no relation with the $\mathrm{K}^{+}$flux into the matrix can be affirmed. This observation is in line with the results reported for pinacidil in the same experimental model by Toleikis' group (Kopustinskiene et al. 2010), who found a $\mathrm{K}^{+}$-independent decrease in State 3 and, also in uncoupled respiration, in the presence of complex I respiratory substrates.

It has to be mentioned that the most investigated benzopyrane derivate, BMS 191095, was reported to exert cytoprotective effect against a calcium ionophore-induced injury in a skeletal muscle cell line C2C12 (Malinska et al. 2010); the compound promoted cellular survival despite an impaired mitochondrial function, as shown by a decrease in State 3 respiration. Interestingly, cytoprotection against calcium overload elicited by the specific $\mathrm{mK}_{\text {ATP }}$ opener was not reversed in this model by $5-\mathrm{HD}$, the channel in-

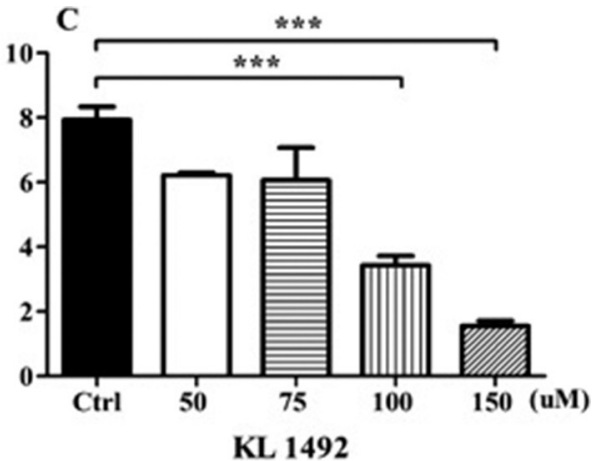

C

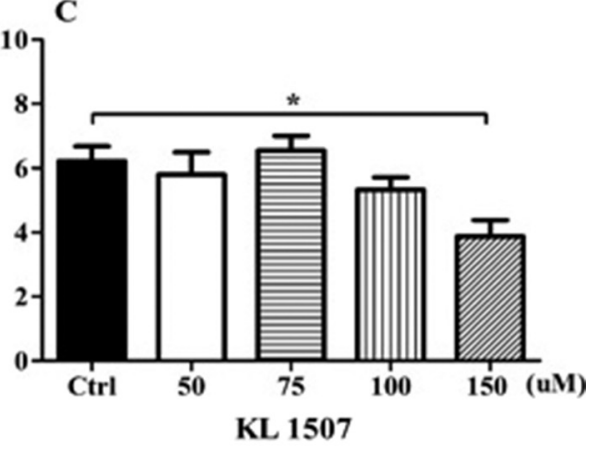

Table 2. HRR studies for CI-supported respiration in the presence of 5-hydroxydecanoic acid (5-HD).

\begin{tabular}{lccc}
\hline & OXPHOS & State 4 & RCR \\
\hline Ctrl & $\mathbf{7 1 1 . 8} \pm \mathbf{8 7 . 2}$ & $\mathbf{6 8 . 5} \pm 7.3$ & $\mathbf{8 . 2 \pm 1 . 1}$ \\
KL-1487 & $183.6 \pm 13.5^{*}$ & $134.5 \pm 17.61^{*}$ & $1.929 \pm 0.35^{*}$ \\
KL-1487 + 5-HD & $185.8 \pm 17.03^{*}$ & $135.4 \pm 40.4^{*}$ & $1.7 \pm 0.5^{*}$ \\
Ctrl & $\mathbf{5 8 9 . 5} \pm 43.65$ & $\mathbf{7 2 . 3 7 \pm 3 . 5}$ & $\mathbf{7 . 9 2 7 \pm 0 . 4 1}$ \\
KL-1492 & $250.8 \pm 39.81^{*}$ & $174.3 \pm 25.85^{*}$ & $1.553 \pm 0.2^{*}$ \\
KL-1492 + 5-HD & $242.6 \pm 27.3^{*}$ & $214.2 \pm 23.8^{*}$ & $1.15 \pm 0.55^{*}$ \\
Ctrl & $\mathbf{4 4 3 . 4 \pm 3 7}$ & $\mathbf{7 4 . 6 1} \pm 5.2$ & $\mathbf{6 . 6 \pm 0 . 7 1}$ \\
KL-1495 & $192.1 \pm 46.07^{*}$ & $147.2 \pm 6.2^{*}$ & $1.383 \pm 0.3^{*}$ \\
KL-1495 + 5-HD & $212.3 \pm 32.22^{*}$ & $153.4 \pm 13^{*}$ & $1.45 \pm 0.3^{*}$ \\
Ctrl & $\mathbf{6 5 6 . 4 \pm 4 9 . 0 4}$ & $\mathbf{5 5 . 2 8} \pm 3.25$ & $\mathbf{6 . 2 2} \pm 0.46$ \\
KL-1507 & $339.5 \pm 42.16^{*}$ & $151.0 \pm 7.7^{*}$ & $3.8 \pm 0.5^{*}$ \\
KL-1507 + 5-HD & $341.2 \pm 32.6^{*}$ & $155.1 \pm 9^{*}$ & $3.3 \pm 0.3^{*}$ \\
\hline
\end{tabular}

Note: Data are expressed in pmol/(s.mL). Values are means \pm SEM $\left({ }^{*} p<0.05\right.$ vs. Ctrl.).

hibitor applied in high concentration $(500 \mu \mathrm{mol} / \mathrm{L})$. Whether this might be related to the previously reported inhibition of respiration by high concentrations ( 100 and $300 \mu \mathrm{mol} / \mathrm{L}$ ) of 5-HD is not known (Lim et al. 2002). Moreover, the beneficial neuroprotective effects of BMS 191095 against cerebral ischemia could be reversed only when 5-HD was applied in very high (10 and $20 \mathrm{mmol} / \mathrm{L})$ concentrations (Mayanagi et al. 2007). However, it cannot be ruled out in these models that, as shown for diazoxide, the ability of 5-HD to reverse protection elicited by channel openers is related to its metabolic effects and does not result from $\mathrm{mK}_{\mathrm{ATP}}$ inhibition (Hanley et al. 2005).

Collectively, our data show a significant uncoupling effect of these novel benzopyran analogues at 100 and $150 \mu \mathrm{mol} / \mathrm{L}$ concentration and the inhibition of mitochondrial respiration when the compounds were applied in the highest concentration $(150 \mu \mathrm{mol} / \mathrm{L})$ in isolated rat heart mitochondria. These effects are not related to the activation of $\mathrm{mK}_{\mathrm{ATP}}$ channels, but they are rather suggestive for a protonophoric action, as reported for the prototype $\mathrm{mK}_{\mathrm{ATP}}$ openers, diazoxide, in the pioneering studies of 
Fig. 5. HRR studies for OXPHOS rates in choline chloride (ChoCl) medium vs. $\mathrm{KCl}$ medium. Results are expressed in pmol/(s·ml). Values are means $\pm \operatorname{SEM}\left({ }^{*} p<0.05 ;{ }^{* *} p<0.01\right.$ vs. Ctrl).
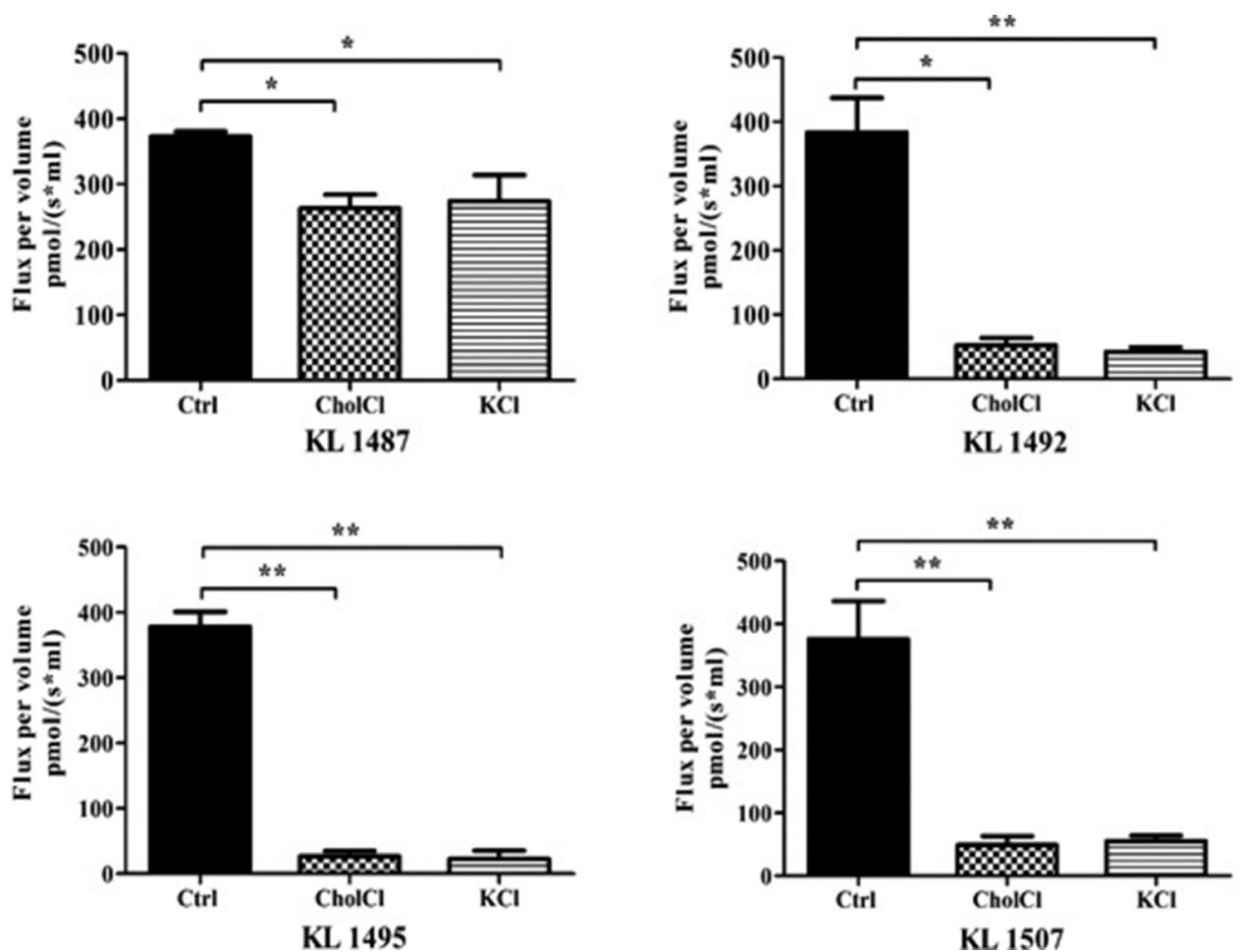

Fig. 6. Assessment of $\mathrm{H}_{2} \mathrm{O}_{2}$ release in mitochondria respiring on glutamate/malate. Results are expressed in pmol/(mg prot·min). Values are means \pm SEM $\left({ }^{*} p<0.05 ;{ }^{* *} p<0.01 ;{ }^{* * *} p<0.001\right.$ vs. Ctrl).
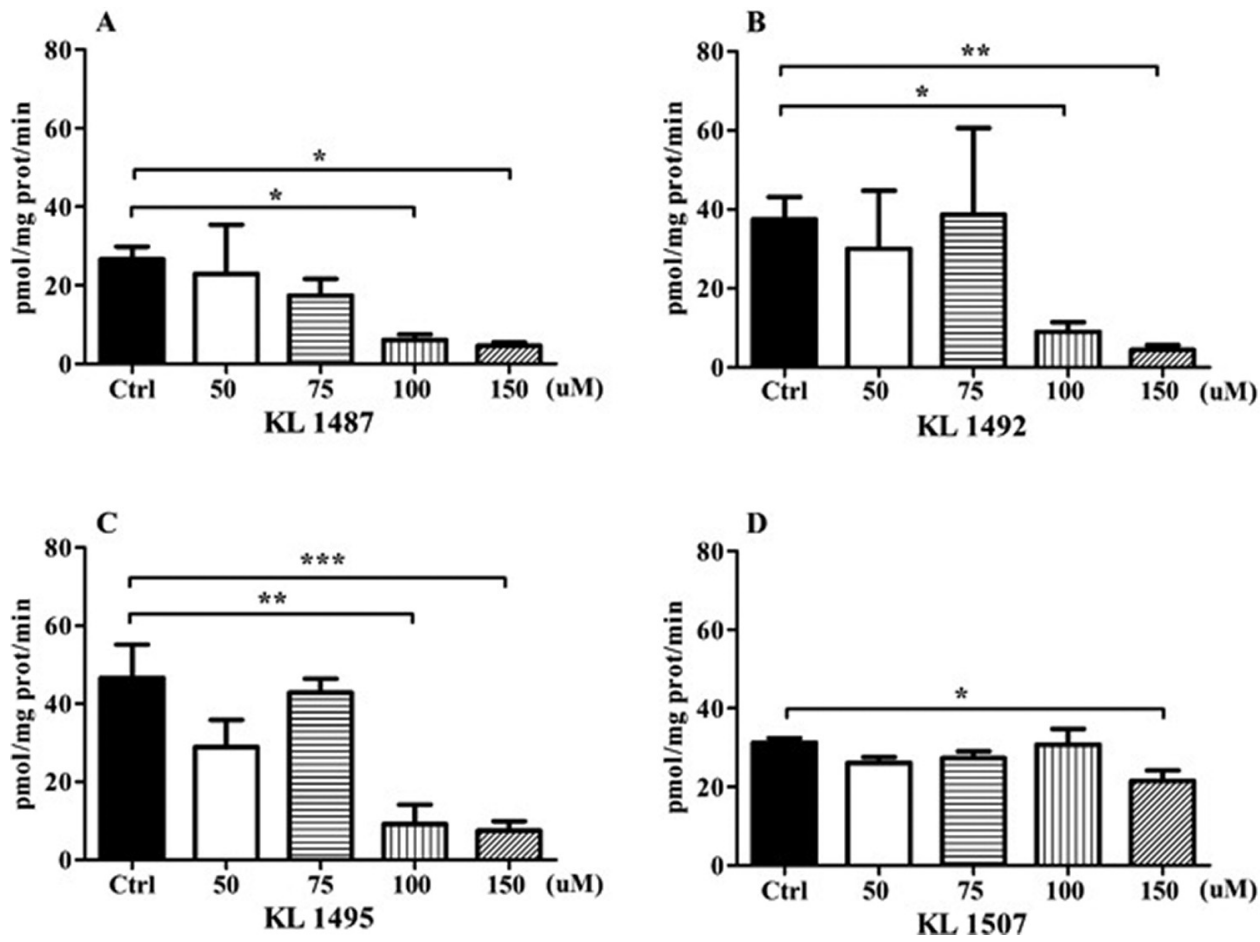

Portenhauser et al. (1971) and more recently, for diazoxide and pinacidil (Holmuhamedov et al. 2004; Kowaltowski et al. 2001).

However, several issues that remain to be clarified can be regarded as limitations of the present study. First, assessing the effect of BSA on the uncoupling effect is worthy, since it has been reported that the uncoupling effect of diazoxide was significantly

depressed by BSA in the incubation medium (Kopustinskiene et al. 2010). Furthermore, since the uncoupling effect can also be determined by the opening of the mitochondrial permeability transition pore (MPTP), the effect of a MPTP desensitizer (e.g., cyclosporine A) on the increased State 4 respiratory rates will be assessed. 


\section{Mitochondrial $\mathrm{H}_{2} \mathrm{O}_{2}$ production}

In the second part of the study we addressed the effect of these four benzopyran compounds on ROS released by isolated mitochondria respiring in the presence of CI substrates (glutamatemalate), using the Amplex Red assay. Our results show a significant decrease of mitochondrial $\mathrm{H}_{2} \mathrm{O}_{2}$ for the first three compounds (KL-1487, KL-1492, and KL-1495) when applied at 100 and $150 \mu \mathrm{mol} / \mathrm{L}$ (Fig. 6) and only in the presence of the highest concentration in the case of KL-1507, respectively (Fig. 6). Interestingly, the last compound KL-1507 showed a slight increase in ROS production when applied at $100 \mu \mathrm{mol} / \mathrm{L}$, whereas the highest concentration elicited a significant decrease of $\mathrm{H}_{2} \mathrm{O}_{2}$ release (Fig. 6).

Our data confirm previous studies reporting on the ability of the $\mathrm{mK}_{\mathrm{ATP}}$ openers to protect mitochondria function and structure by suppressing ROS generation during reoxygenation (Ferranti et al. 2003; Ozcan et al. 2002; Vanden Hoek et al. 2000).

In the past decade the interest of the scientific community largely moved towards the pharmacological modulation of the mitochondrial permeability transition pore (mPTP) as novel mitochondrial target for cardioprotection (recently reviewed in Bernardi and Di Lisa (2015)), while studies addressing $\mathrm{mK}_{\mathrm{ATP}}$ channels mainly attempted to elucidate its structure (Foster et al. 2012). Besides the unequivocal role of $\mathrm{mK}_{\mathrm{ATP}}$ openers in reducing infarct size, an emerging research direction is represented by their role in preserving the electrical stability of the heart (reviewed in Muntean et al. (2015)). Interestingly, a functional crosstalk between $\mathrm{mPTP}$ and $\mathrm{mK}_{\mathrm{ATP}}$ that determined the arrhythmic vulnerability to oxidative stress has been recently reported (Xie et al. 2014).

The selective benzopyran derivate, BMS 191095, elicited both antinecrotic (Neckar et al. 2002) and antiarrhythmic (Fischbach et al. 2004) protection in the rodent heart subjected to I/R injury, being recognized as an useful tool for basic research (Grover and Atwal 2002). Accordingly, further studies addressing the role of novel benzopyran analogues in preventing the deleterious effects of reperfusion injury are warranted. Whether their above reported effects can be recapitulated in the settings of $I / R$ injury remains to be demonstrated. Indeed, different behaviours may arise in pathological conditions, since as pointed out in a critical review by Brookes (2005), "uncoupling of mitochondria decreases ROS but uncoupling of inhibited mitochondria increases ROS".

Nevertheless, $\mathrm{mK}_{\text {ATP }}$ and $\mathrm{mPTP}$ represent targets for pharmacological interventions that could be jointly applied to mitigate one of the major consequences of mitochondria dysfunction, namely the oxidative stress, and thus to provide better cardioprotection.

\section{Conclusions}

KL-1487, KL-1492, KL-1495, and KL-1507 are novel benzopyran analogues with protonophoric properties that modulate mitochondrial respiratory function and hydrogen peroxide release in isolated rat heart mitochondria respiring on physiological complex I substrates. High-resolution respirometry studies conducted in the presence of the pharmacological modulators of $\mathrm{mK}_{\mathrm{ATP}}$ revealed the uncoupling effect and respiratory inhibition, respectively, in a $\mathrm{K}^{+}$independent manner. Moreover, when applied in the highest concentrations, all the investigated compounds decreased $\mathrm{H}_{2} \mathrm{O}_{2}$ release. Whether these effects can be associated with cardioprotection in the setting of ischemia/reperfusion injury remains to be demonstrated.

\section{Acknowledgements}

This work was supported by a grant of the Ministry of National Education, CNCS - UEFISCDI, project number PN-II-ID-PCE-2012-4$0512(\mathrm{NJ})$ and by the doctoral fellowship POSDRU No. 159/1.5/S/ 136893 - DocMed.Net_2.0 (AP). We would like to thank Ms. Andreea Privistirescu (PhD student), and Mircea Hancu (electronic engineer) at the Department of Pathophysiology, "Victor Babes" Uni- versity of Medicine and Pharmacy, Timisoara for their valuable contribution to the study. The author disclose that there are no conflicts of interest.

\section{References}

Ardehali, H., and O'Rourke, B. 2005. Mitochondrial K(ATP) Channels in Cell Survival and Death. J. Mol. Cell. Cardiol. 39(1): 7-16. doi:10.1016/j.yjmcc.2004. 12.003. PMID:15978901.

Bernardi, P., and Di, Lisa, F. 2015. The Mitochondrial Permeability Transition Pore: Molecular Nature and Role as a Target in Cardioprotection. J. Mol. Cell. Cardiol. 78: 100-106. doi:10.1016/j.yjmcc.2014.09.023. PMID:25268651.

Breschi, M.C., Calderone, V., Martelli, A., Minutolo, F., Rapposelli, S., Testai, L., et al. 2006. New Benzopyran-based Openers of the Mitochondrial ATPsensitive Potassium Channel with Potent Anti-Ischemic Properties. J. Med. Chem. 49(26): 7600-7602. doi:10.1021/jm0612281. PMID:17181142.

Brookes, P.S. 2005. Mitochondrial H(+) Leak and ROS Generation: an Odd Couple. Free Radic. Biol. Med. 38(1): 12-23. doi:10.1016/j.freeradbiomed.2004.10.016. PMID:15589367.

Camara, A.K., Bienengraeber, M., and Stowe, D.F. 2011. Mitochondrial Approaches to Protect Against Cardiac Ischemia and Reperfusion Injury. Front. Physiol. 2: 13. doi:10.3389/fphys.2011.00013. PMID:21559063.

Cardoso, A.R., Queliconi, B.B., and Kowaltowski, A.J. 2010. Mitochondrial Ion Transport Pathways: Role in Metabolic Diseases. Biochim. Biophys. Acta, 1797(6-7): 832-838. doi:10.1016/j.bbabio.2009.12.017. PMID:20044972.

Di, Lisa, F. 2001. Mitochondrial Contribution in the Progression of Cardiac Ischemic Injury. IUBMB Life, 52(3-5): 255-261. doi:10.1080/15216540152846073. PMID:11798040.

Di, Lisa, F., Canton, M., Menabo, R., Kaludercic, N., and Bernardi, P. 2007. Mitochondria and Cardioprotection. Heart Fail. Rev. 12(3-4): 249-260. doi:10.1007/ s10741-007-9028-z. PMID:17516167.

Drose, S., Brandt, U., and Hanley, P.J. 2006. K+-independent actions of diazoxide question the role of inner membrane KATP channels in mitochondrial cytoprotective signaling. The Journal of biological chemistry. 281(33): 2373323739. PMID:16709571.

Duicu, O.M., Mirica, S.N., Gheorgheosu, D.E., Privistirescu, A.I., Fira-Mladinescu, O., and Muntean, D.M. 2013. Ageing-induced Decrease in Cardiac Mitochondrial Function in Healthy Rats. Can. J. Physiol. Pharmacol. 91(8): 593-600. doi:10.1139/ cjpp-2012-0422. PMID:23889593.

Ferranti, R., da Silva, M.M., and Kowaltowski, A.J. 2003. Mitochondrial ATPsensitive K+ Channel Opening Decreases Reactive Oxygen Species Generation. FEBS Lett. 536(1-3): 51-55. doi:10.1016/S0014-5793(03)00007-3. PMID: 12586337.

Fischbach, P.S., White, A., Barrett, T.D., and Lucchesi, B.R. 2004. Risk of Ventricular Proarrhythmia with Selective Opening of the Myocardial Sarcolemmal versus Mitochondrial ATP-gated Potassium Channel. J. Pharmacol. Exp. Ther. 309(2): 554-559. doi:10.1124/jpet.103.060780. PMID:14747611.

Forbes, R.A., Steenbergen, C., and Murphy, E. 2001. Diazoxide-induced Cardioprotection Requires Signaling through a Redox-sensitive Mechanism. Circ. Res. 88(8): 802-809. doi:10.1161/hh0801.089342. PMID:11325872.

Foster, D.B., Ho, A.S., Rucker, J., Garlid, A.O., Chen, L., Sidor, A., et al. 2012. Mitochondrial ROMK Channel is a Molecular Component of MitoK(ATP). Circ. Res. 111(4): 446-454. doi:10.1161/CIRCRESAHA.112.266445. PMID:22811560.

Garlid, K.D., and Halestrap, A.P. 2012. The Mitochondrial K(ATP) Channel-Fact or Fiction? J. Mol. Cell. Cardiol. 52(3): 578-583. doi:10.1016/j.yjmcc.2011.12.011. PMID:22240339.

Gaspar, T., Snipes, J.A., Busija, A.R., Kis, B., Domoki, F., Bari, F., et al. 2008. ROS-Independent Preconditioning in Neurons via Activation of MitoK(ATP) Channels by BMS-191095. J. Cereb. Blood Flow Metab. 28(6): 1090-1103. doi: 10.1038/sj.jcbfm.9600611. PMID:18212794.

Gornall, A.G., Bardawill, C.J., and David, M.M. 1949. Determination of Serum Proteins by Means of the Biuret Reaction. J. Biol. Chem. 177(2): 751-766. PMID:18110453.

Grover, G.J., and Atwal, K.S. 2002. Pharmacologic Profile of the Selective Mitochondrial-K(ATP) Opener BMS-191095 for Treatment of Acute Myocardial Ischemia. Cardiovasc. Drug Rev. 20(2): 121-136. doi:10.1111/j.1527-3466.2002. tb00187.x. PMID:12177690.

Grover, G.J., D’Alonzo, A.J., Garlid, K.D., Bajgar, R., Lodge, N.J., Sleph, P.G., et al. 2001. Pharmacologic Characterization of BMS-191095, a Mitochondrial K(ATP) Opener with no Peripheral Vasodilator or Cardiac Action Potential Shortening Activity. J. Pharmacol. Exp. Ther. 297(3): 1184-1192. PMID:11356945.

Grover, G.J., D’Alonzo, A.J., Darbenzio, R.B., Parham, C.S., Hess, T.A., and Bathala, M.S. 2002. In Vivo Characterization of the Mitochondrial Selective K(ATP) Opener (3R)-trans-4-((4-chlorophenyl)-N-(1H-imidazol-2-ylmethyl)dimethyl2H-1-benzopyran-6-carbonitril monohydrochloride (BMS-191095): Cardioprotective, Hemodynamic, and Electrophysiological Effects. J. Pharmacol. Exp. Ther. 303(1): 132-140. doi:10.1124/jpet.102.036988. PMID:12235243.

Hanley, P.J., and Daut, J. 2005. K(ATP) Channels and Preconditioning: a Reexamination of the Role of Mitochondrial K(ATP) Channels and an Overview of Alternative Mechanisms. J. Mol. Cell. Cardiol. 39(1): 17-50. doi:10.1016/j. yjmcc.2005.04.002. PMID:15907927.

Hanley, P.J., Mickel, M., Loffler, M., Brandt, U., and Daut, J. 2002. K(ATP) Channel- 
independent Targets of Diazoxide and 5-Hydroxydecanoate in the Heart. J. Physiol. 542(3): 735-741. doi:10.1113/jphysiol.2002.023960. PMID:12154175.

Hanley, P.J., Drose, S., Brandt, U., Lareau, R.A., Banerjee, A.L., Srivastava, D.K. et al. 2005. 5-Hydroxydecanoate is Metabolised in Mitochondria and Creates a Rate-limiting Bottleneck for Beta-oxidation of Fatty Acids. J. Physiol. 562(2): 307-318. doi:10.1113/jphysiol.2004.073932. PMID:15513944.

Holmuhamedov, E.L., Jahangir, A., Oberlin, A., Komarov, A., Colombini, M., and Terzic, A. 2004. Potassium Channel Openers are Uncoupling Protonophores: Implication in Cardioprotection. FEBS Lett. 568(1-3): 167-170. doi:10.1016/j. febslet.2004.05.031. PMID:15196941.

Kopustinskiene, D.M., Jovaisiene, J., Liobikas, J., and Toleikis, A. 2002. Diazoxide and Pinacidil Uncouple Pyruvate-Malate-Induced Mitochondrial Respiration. J. Bioenerg. Biomembr. 34(1): 49-53. doi:10.1023/A:1013870704002. PMID: 11860180.

Kopustinskiene, D.M., Liobikas, J., Skemiene, K., Malinauskas, F., and Toleikis, A. 2010. Direct Effects of K(ATP) Channel Openers Pinacidil and Diazoxide on Oxidative Phosphorylation of Mitochondria in Situ. Cell. Physiol. Biochem. 25(2-3): 181-186. doi:10.1159/000276552. PMID:20110678.

Korotkov, S.M., Nesterov, V.P., and Ryabchikov, N.N. 2006. Study of the Mechanism of Action of Diazoxide on Rat Heart Mitochondria under Calcium Loading. Dokl. Biochem. Biophys. 408: 133-137. doi:10.1134/S1607672906030070. PMID:16913412.

Kowaltowski, A.J., Seetharaman, S., Paucek, P., and Garlid, K.D. 2001. Bioenergetic Consequences of Opening the ATP-sensitive $\mathrm{K}(+)$ Channel of Heart Mitochondria. Am. J. Physiol. Heart Circ. Physiol. 280(2): H649-H657. PMID: 11158963.

Krenz, M., Oldenburg, O., Wimpee, H., Cohen, M.V., Garlid, K.D., Critz, S.D., et al. 2002. Opening of ATP-sensitive Potassium Channels Causes Generation of Free Radicals in Vascular Smooth Muscle Cells. Basic Res. Cardiol. 97(5): 365-373. doi:10.1007/s003950200045. PMID:12200636.

Lim, K.H., Javadov, S.A., Das, M., Clarke, S.J., Suleiman, M.S., and Halestrap, A.P. 2002. The Effects of Ischaemic Preconditioning, Diazoxide and 5-Hydroxydecanoate on Rat Heart Mitochondrial Volume and Respiration. J. Physiol. 545(3): 961-974. doi:10.1113/jphysiol.2002.031484. PMID:12482899.

Liu, Y., Sato, T., O'Rourke, B., and Marban, E. 1998. Mitochondrial ATPdependent Potassium Channels: Novel Effectors of Cardioprotection? Circulation, 97(24): 2463-2469. doi:10.1161/01.CIR.97.24.2463. PMID:9641699.

Malinska, D., Kulawiak, B., Wrzosek, A., Kunz, W.S., and Szewczyk, A. 2010. The Cytoprotective Action of the Potassium Channel Opener BMS-191095 in C2C12 Myoblasts is Related to the Modulation of Calcium Homeostasis. Cell. Physiol. Biochem. 26(2): 235-246. doi:10.1159/000320523. PMID:20798507.

Mannhold, R. 2004. KATP Channel Openers: Structure-activity Relationships and Therapeutic Potential. Med. Res. Rev. 24(2): 213-266. doi:10.1002/med.10060. PMID:14705169.

Mayanagi, K., Gaspar, T., Katakam, P.V., Kis, B., and Busija, D.W. 2007. The Mitochondrial K(ATP) Channel Opener BMS-191095 Reduces Neuronal Dam- age After Transient Focal Cerebral Ischemia in Rats. J. Cereb. Blood Flow Metab. 27(2): 348-355. doi:10.1038/sj.jcbfm.9600345. PMID:16736040.

Muntean, D.M., Kiss, L., Jost, N., and Baczko, I. 2015. ATP-Sensitive Potassium Channel Modulators and Cardiac Arrhythmias: An Update. Curr. Pharm. Des. 21(8): 1091-1102. doi:10.2174/1381612820666141029102800. PMID:25354183.

Neckar, J., Szarszoi, O., Koten, L., Papousek, F., Ost'adal, B., Grover, G.J., et al. 2002. Effects of Mitochondrial K(ATP) Modulators on Cardioprotection Induced by Chronic High Altitude Hypoxia in Rats. Cardiovasc. Res. 55(3): 567575. doi:10.1016/S0008-6363(02)00456-X. PMID:12160954.

Nishida, H., Matsumoto, A., Tomono, N., Hanakai, T., Harada, S., and Nakaya, H. 2010. Biochemistry and Physiology of Mitochondrial Ion Channels Involved in Cardioprotection. FEBS Lett. 584(10): 2161-2166. doi:10.1016/j.febslet.2009. 12.033. PMID:20035754.

Ozcan, C., Bienengraeber, M., Dzeja, P.P., and Terzic, A. 2002. Potassium Channel Openers Protect Cardiac Mitochondria by Attenuating Oxidant Stress at Reoxygenation. Am. J. Physiol. Heart Circ. Physiol. 282(2): H531-H539. doi:10. 1152/ajpheart.00552.2001. PMID:11788400.

Pain, T., Yang, X.M., Critz, S.D., Yue, Y., Nakano, A., Liu, G.S., et al. 2000. Opening of Mitochondrial K(ATP) Channels Triggers the Preconditioned State by Generating Free Radicals. Circ. Res. 87(6): 460-466. doi:10.1161/01.RES.87.6.460. PMID:10988237.

Paucek, P., Mironova, G., Mahdi, F., Beavis, A.D., Woldegiorgis, G., and Garlid, K.D. 1992. Reconstitution and Partial Purification of the Glibenclamidesensitive, ATP-dependent K+ Channel from Rat Liver and Beef Heart Mitochondria. J. Biol. Chem. 267(36): 26062-26069. PMID:1464617.

Portenhauser, R., Schafer, G., and Trolp, R. 1971. Inhibition of Mitochondrial Metabolism by the Diabetogenic Thiadiazine Diazoxide. II. Interaction with Energy Conservation and Ion Transport. Biochem. Pharmacol. 20(10): 26232632. PMID:4255929.

Rousou, A.J., Ericsson, M., Federman, M., Levitsky, S., and McCully, J.D. 2004. Opening of Mitochondrial KATP Channels Enhances Cardioprotection Through the Modulation of Mitochondrial Matrix Volume, Calcium Accumulation, and Respiration. Am. J. Physiol. Heart Circ. Physiol. 287(5): H1967H1976. doi:10.1152/ajpheart.00338.2004. PMID:15242834.

Terada, H. 1990. [Platelet Dysfunction in Diabetes Mellitus]. Nihon Rinsho, 48(Suppl.): 738-745. PMID:2150865.

Turrens, J.F. 2003. Mitochondrial Formation of Reactive Oxygen Species. J. Physiol. 552(2): 335-344. doi:10.1113/jphysiol.2003.049478. PMID:14561818.

Vanden Hoek, T., Becker, L.B., Shao, Z.H., Li, C.Q., and Schumacker, P.T. 2000. Preconditioning in Cardiomyocytes Protects by Attenuating Oxidant Stress at Reperfusion. Circ. Res. 86(5): 541-548. doi:10.1161/01.RES.86.5.541. PMID: 10720416.

Xie, C., Kauffman, J., and Akar, F.G. 2014. Functional Crosstalk Between the Mitochondrial PTP and KATP Channels Determine Arrhythmic Vulnerability to Oxidative Stress. Front. Physiol. 5: 264. doi:10.3389/fphys.2014.00264. PMID:25076913. 